Table 1. Efficacy scores proposed by a PsA expert group and consensus achieved by an online survey among PsA treating physicians Efficacy scores for different drugs and manifestations range from 0 (no effect) to 5 (maximal effect). Green fields indicate, that at least $65 \%$ of the survey participants agreed on the proposed efficacy score.

\begin{tabular}{lcccccc}
\hline & $\begin{array}{c}\text { Peripheral } \\
\text { arthritis }\end{array}$ & $\begin{array}{c}\text { Axial } \\
\text { disease }\end{array}$ & Enthesitis & Dactylitis & $\begin{array}{c}\text { Skin } \\
\text { disease }\end{array}$ & $\begin{array}{c}\text { Nail } \\
\text { disease }\end{array}$ \\
\hline Methotrexat & 2.5 & 0 & 0 & 1 & 2.5 & 1.5 \\
Sulfasalazin & 1 & 0 & 0 & 0 & 0 & 0 \\
Leflunomid & 2.5 & 0 & 0 & 1 & 1 & 1 \\
Apremilast & 3 & 1 & 3 & 2.5 & 3 & 3 \\
Etanercept & 4 & 4 & 4 & 3.5 & 3 & 3.5 \\
Infliximab & 4 & 4 & 4 & 4 & 4 & 4 \\
Adalimumab & 4 & 4 & 4 & 4 & 4 & 4.5 \\
Golimumab & 4 & 4 & 4 & 4 & 3 & 3 \\
Certolizumab & 4 & 4 & 4 & 4 & 4 & 4 \\
$\quad \begin{array}{l}\text { pegol } \\
\text { Ustekinumab }\end{array}$ & 3.5 & 2.5 & 4.5 & 3 & 4.5 & 4 \\
Secukinumab & 4 & 4 & 4 & 4 & 5 & 4.5 \\
Abatacept & 3.5 & 0 & 0 & 0 & 1.5 & 0 \\
\hline
\end{tabular}

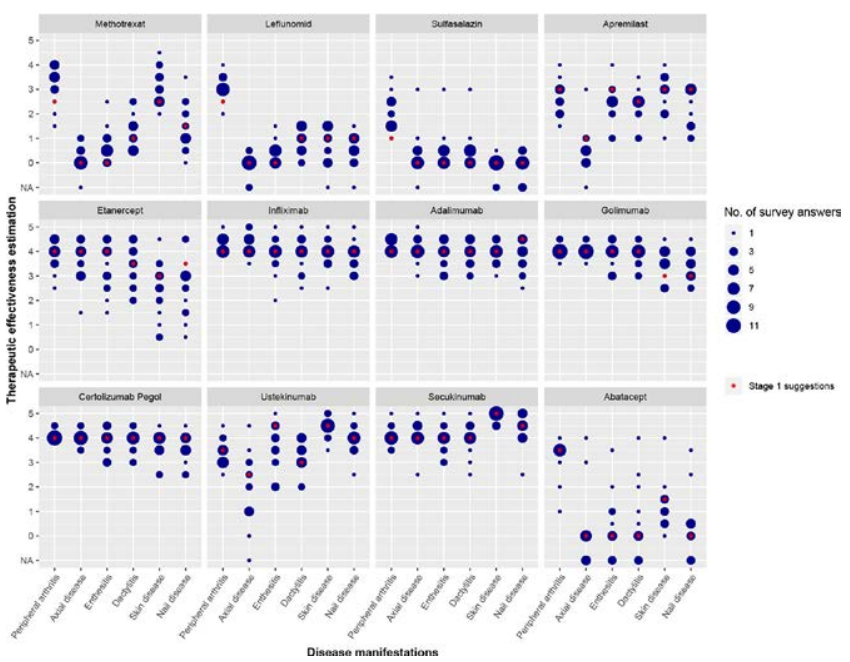

Figure 1. Results from an online survey among physicians querying their perception of efficacies of PsA drugs on different manifestations. Therapeutic effectiveness is estimated by the participants on a scale from 0 (no effect) to 5 (maximal effectiveness); NA = no answer. The size of the dots relates to the number of answers given. Red stars indicate the scores proposed by the initial expert group.

Conclusion: Many treatments are available to be used in PsA. The usage of treatment classes seems to depend on experience level and mode of action. Higher agreement on efficacy in specific diseases manifestation was achieved in the class of biologics whereas the opinion on efficacy of csDMARDs in general is divergent. Strategies are needed to guide physicians with lower level of experience in the use of specific drugs to achieve an optimised patient care level using personalized treatment strategies.

Disclosure of Interests: Timm Oberwahrenbrock Grant/research support from: BMS, Hannah Tian: None declared, Diamant Thaçi Grant/research support from: Janssen Research \& Development, LLC, Klaus Krueger Consultant of: Celgene, Jürgen Wollenhaupt Consultant of: Celgene, Michaela Köhm Grant/research support from: Pfizer, Janssen, BMS, LEO, Consultant of: BMS, Pfizer, Speakers bureau: Pfizer, BMS, Janssen, Novartis, Frank Behrens Grant/research support from: Pfizer, Janssen, Chugai, Celgene, Lilly and Roche, Consultant of: Pfizer, AbbVie, Sanofi, Lilly, Novartis, Genzyme, Boehringer, Janssen, MSD, Celgene, Roche and Chugai

DOI: 10.1136/annrheumdis-2020-eular.5484

\section{AB1290-HPR UTILITY OF FRAX IN THE RISK DETECTION OF FRACTURE IN SPONDYLOARTHRITIS}

D. Palma Sanchez ${ }^{1}$, A. Haro ${ }^{1}$, M. J. Moreno ${ }^{1}$, E. Peñas ${ }^{1}$, M. Mayor ${ }^{1}$, M. Moreno ${ }^{2}$, L. F. Linares Ferrando ${ }^{2} .^{1} \mathrm{H}$. Rafael Méndez, Rheumatology, Lorca, Spain; ${ }^{2} \mathrm{H}$. Virgen de la Arrixaca, Rheumatology, Murcia, Spain

Background: Axial spondyloarthritis (SpAax) presents an increased risk of vertebral fracture not fully detected by Dual energy X-ray absorptiometry (DXA). The FRAX algorithms give the 10-year probability of hip fracture and of mayor osteoporotic fracture (clinical spine, forearm, hip or shoulder fracture), taking into account 11 clinical risk factors.

Objectives: To analyze the suitability of FRAX to detect the risk of fracture in patients with SpAax. To assess whether the incorporation of SpAax as a clinical risk factor to conventional FRAX provides additional information.

Methods: Cross-sectional study in which SpAax patients (ASAS criteria) were included. Clinical-demographic and related to the disease variables were collected. FRIDEX model for Spanish population was used to determine low, inter mediate or high risk of mayor fracture by FRAX. These results were compared with those obtained by DXA and trabecular bone score (TBS). In the statistical analysis we used mean and standard deviation (SD) in quantitative variables and frequency in qualitative ones. To compare means among 3 groups, ANOVA test was used.

Results: The characteristics of the patients are shown in Table 1. According to FRIDEX, no patient had high risk of fracture and $2.4 \%$ had intermediate risk. When SpAax was added as a risk factor, no patient had high risk of fracture and $6.1 \%$ presented intermediate risk. According to DXA, $7.3 \%$ had high risk of fracture and $41.3 \%$ intermediate risk. TBS detected high risk of fracture in $18.3 \%$ and intermediate risk also in $18.3 \%$ of patients.

Table 1. Sociodemographic, clinical and related characteristics with the disease (BMD: bone mineral density, BMI: index of body mass)

Gender (Male), n (\%)

Age, mean \pm SD

BMI, mean \pm SD

Smoking, $\mathrm{n}(\%)$

Diabetes mellitus, $\mathrm{n}(\%)$

Osteoporotic fracture, $\mathrm{n}(\%)$

Disease duration (years), mean $\pm \mathrm{SD}$

syndesmophytes, $\mathrm{n}(\%)$

ASDAS-PCR, mean + SD

Lumbar BMD $\left(\mathrm{g} / \mathrm{cm}^{2}\right)$, mean $\pm \mathrm{SD}$

BMD femoral neck $\left(\mathrm{g} / \mathrm{cm}^{2}\right)$, mean $\pm \mathrm{SD}$

Lumbar TBS, mean \pm SD

$61(74.4)$

$49.48 \pm 12.47$

$27.13 \pm 4.42$

26 (31.7)

$9(11)$

$1(1.2)$

$11.77 \pm 10$

$38(46.3)$

$2.55 \pm 1.07$

$1.032 \pm 0.180$

$0.816 \pm 0.140$

$1.383 \pm 0.133$

Conclusion: FRAX does not seem an adequate tool to detect the risk of fracture in patients with SpAax since it did not improve the results obtained by DXA meanwhile TBS did. The incorporation of SpAax as a clinical risk factor to conventional FRAX did not provide additional information in most cases

Disclosure of Interests: None declared

DOI: 10.1136/annrheumdis-2020-eular.3839

\section{AB1291-HPR IMPLEMENTATION OF AN ELECTRONIC SYSTEM FOR ISSUING PRESCRIPTIONS IN PATIENTS WITH RHEUMATIC DISEASES}

L. Santoyo-Fexas ${ }^{1}$, R. A. Uriarte Botello ${ }^{1}$, C. V. Solis ${ }^{1}$, B. R. Vázquez Fuentes ${ }^{1}$,

C. M. Skinner Taylor ${ }^{1}$, I. D. J. Hernandez-Galarza ${ }^{1}$, M. Eguia Bernal' ${ }^{1}$, D.

Á. Galarza-Delgado'. ' Hospital Universitario "Dr. José Eleuterio González",

Rheumatology Service, Monterrey, Mexico

Background: Pharmacovigilance is the science and activities related to detection, evaluation, understanding and prevention of adverse effects of medications or any other health problem related to them. (1)

Within the scope of the pharmacovigilance study, following domains are included: adverse drug reaction, interaction between medications, counterfeit or inferior quality medications, lack of efficacy of medications, misuse or abuse of medications and medication errors (ME). (2)

$\mathrm{ME}$ is any preventable incident that can cause harm to the patient or lead to improper use of medications when they are under the control of healthcare professionals or the patient. (3)

Objectives: To determine the frequency of ME in the prescriptions among rheumatology outpatient's clinic

Methods: Prospective observational study.

Frequency of ME was sought by a randomized review of the prescriptions from rheumatology outpatient's clinic of the University Hospital "Dr. José Eleuterio González" before and after the implementation of an electronic medical prescription system (REPAIR®) (January 2018-December 2019)

REPAIR $\circledast$ displays an automated menu with the stages of the medical prescription: Name, presentation and dosage of the medicine and duration of the treatment. Figure 1. Once the review began, semiannual reports were made to the doctors involved in which frequency of errors and the stage of medical prescription with highest incidence of ME were reported. 


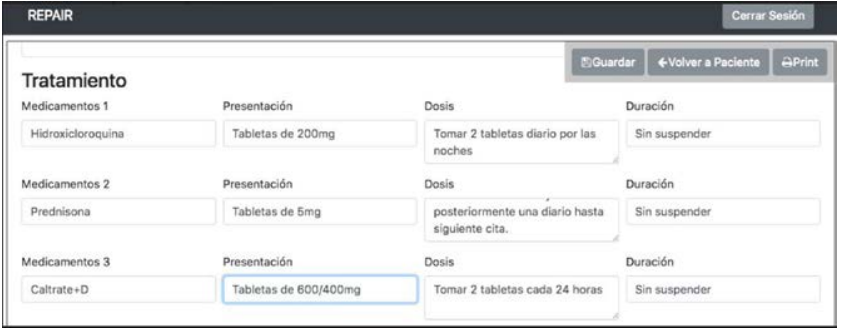

Figure 1 Example image displayed by REPAIR $®$

Descriptive statistics were performed, reporting frequencies and percentages. Results: A total of 1599 medical prescriptions were evaluated. The number of prescriptions with ME was 196 (12.2\%). Table 1

\section{Table 1 General description about errors in medical prescriptions}

\begin{tabular}{lc}
\hline Prescriptions evaluated & 1599 \\
Prescription with ME $\mathbf{n}(\%)$ & $196(12.2 \%)$ \\
Medications evaluated $\mathbf{n}$ & 10413 \\
Medications with ME $\mathbf{n}(\%)$ & $907(8.7 \%)$ \\
Average medications per prescription & 6.4 \\
Average medications with ME per prescription & 0.78 \\
Prescription Stage & \\
Name of the drug $\mathbf{n}(\%)$ & $2 / 10413(0.01 \%)$ \\
Medication presentation $\mathbf{n}(\%)$ & $77 / 10413(0.7 \%)$ \\
Dose of the drug $\mathbf{n}(\%)$ & $0 / 10413(0 \%)$ \\
Duration of prescription $\mathbf{n}(\%)$ & $725 / 10413(6.9 \%)$ \\
\hline
\end{tabular}

The incidence of $\mathrm{ME}$ decreased, at beginning of the study incidence was reported $31.6 \%$, and at the end were $1.5 \%$. Graph 1

The percentage of medications with ME also decreased from $17.2 \%$ to $0.8 \%$ at the end of the study. Table 2

Table 2 Errors in prescriptions per semester

\begin{tabular}{|c|c|c|c|c|}
\hline & $\begin{array}{c}\text { January-June } \\
2018\end{array}$ & $\begin{array}{l}\text { July-December } \\
2018\end{array}$ & $\begin{array}{l}\text { January- } \\
\text { June } 2019\end{array}$ & $\begin{array}{l}\text { July- } \\
\text { December } \\
2019\end{array}$ \\
\hline Prescriptions evaluated $n$ & 321 & 411 & 407 & 460 \\
\hline Prescriptions with ME $n(\%)$ & $73(31.6 \%)$ & $93(22.6 \%)$ & $23(5.6 \%)$ & $7(1.5 \%)$ \\
\hline Medications evaluated $\mathbf{n}$ & 2126 & 2784 & 2680 & 2823 \\
\hline Medications with ME n (\%) & $367(17.2 \%)$ & $469(16.8 \%)$ & $36(1.7 \%)$ & $35(0.8 \%)$ \\
\hline $\begin{array}{l}\text { Average medications per } \\
\text { prescription evaluated }\end{array}$ & 6.6 & 6.7 & 6.2 & 6.4 \\
\hline $\begin{array}{l}\text { Average medications per } \\
\text { prescription evaluated }\end{array}$ & 1.146 & 1.143 & 0.082 & 0.081 \\
\hline \multicolumn{5}{|l|}{ Prescription Stage n (\%) } \\
\hline Name & $1 / 367(0.2 \%)$ & $1 / 469(0.2 \%)$ & 0 & 0 \\
\hline Presentation & $37 / 367(10 \%)$ & $37 / 469(7.8 \%)$ & $1 / 36(2.7 \%)$ & $2 / 35(5.7 \%)$ \\
\hline Dose & 0 & 0 & 0 & 0 \\
\hline Duration & $290 / 367(89 \%)$ & $367 / 469(88.2 \%)$ & $35 / 36(97.2 \%)$ & $33 / 35(94.2 \%$ \\
\hline
\end{tabular}

Conclusion: Decrease in the incidence of ME in rheumatology consultation is important because outcome of the patients depends significantly on treatment adherence. This study results shows that through the application of an electronic prescription system, it is possible to reduce the incidence of ME in rheumatology consultation.

References:

[1] Jeetu G, Anusha G. Pharmacovigilance: a worldwide master key for drug safety monitoring. J Young Pharm. 2010;2(3):315-20.

[2] Organization $\mathrm{WH}$. WHO pharmacovigilance indicators: a practical manual for the assessment of pharmacovigilance systems. 2015.

[3] Elden NM, Ismail A. The Importance of Medication Errors Reporting in Improving the Quality of Clinical Care Services. Glob J Health Sci. 2016;8(8):54510.

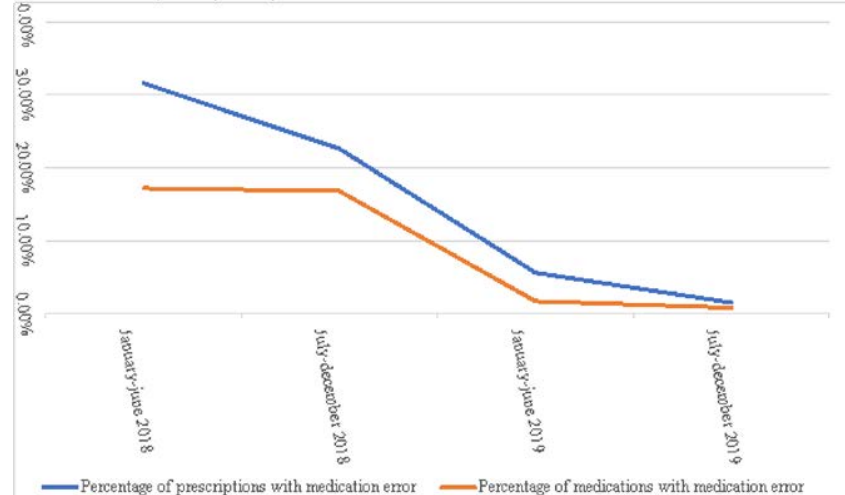

Graph 1

Disclosure of Interests: None declared

DOI: 10.1136/annrheumdis-2020-eular.2218

\section{AB1292-HPR NUMBER OF DRUGS IN THE PRESCRIPTION, A PREDISPOSING FACTOR FOR MEDICATION ERRORS IN RHEUMATOLOGY}

L. Santoyo-Fexas ${ }^{1}$, R. A. Uriarte Botello ${ }^{1}$, B. R. Vázquez Fuentes ${ }^{1}$, C. V. Solis ${ }^{1}$, C. M. Skinner Taylor ${ }^{1}$, I. D. J. Hernandez-Galarza ${ }^{1}$, M. Eguia Bernal ${ }^{1}$, D. Á. Galarza-Delgado'. 'Hospital Universitario "Dr. José Eleuterio González", Rheumatology, Monterrey, Mexico

Background: Medication error can be defined as a failure in the treatment process that leads to or has the potential to lead to harm to the patient, this fault can happen in two different phases: prescribing and prescription.

Prescribing is the process of deciding what to prescribe and naming it. Various types of faults can occur in the decision-making process: underprescribing, overprescribing, irrational, inappropriate and ineffective prescribing. All these covers one type of errors, but these are different kind of errors that those that occur in the act of writing a prescription. This leads to the distinct concepts of 'prescribing faults' and 'prescription errors'

A prescription is 'a written order, which includes detailed instructions of what medicine should be given, to whom, in what formulation and dose, by what route, when, how frequently, and for how long' Thus, a prescription error can be defined as 'a failure in the prescription writing process that results in a wrong instruction about one or more of the normal features of a prescription'. The 'normal features' include the identity of the patient, the identity of the drug, the formulation and dose, and the route, timing, frequency, and duration of administration. (1) It is not record about the rate of medication errors in rheumatology consultation. Objectives: To evaluate whether there is a relationship between prescribing errors and the number of drugs in the prescription.

Methods: A descriptive, observational, and retrospective study was made.

It was carried out a random search of medical prescriptions, generated by the electronic records (REPAIR $\Omega$ ) of the rheumatology consultation of the Hospital Universitario "Dr. José Eleuterio González" during 2019, in which the prescriptions that contained any error were identified

T student test was performed to see the difference in the prescription error based on the number of medications. $\mathrm{P}<0.05$ was taken as statistically significant.

Results: A review of 867 medical prescriptions was performed, among which 5503 medications were indicated with an average of 6.34 medications per prescription, a total of $30(6.9 \%)$ prescriptions were found with error, where a total of $71(3.9 \%)$ medications had errors. In the prescriptions with medication error, all the errors were prescription type; $68(95.7 \%)$ had a mistake in the duration of administration and $3(4.22 \%)$ in the identity of the drug.

In the prescriptions with medical errors the average number of prescription drugs was 7.50 , only $2 / 30(0.6 \%)$ had less than 7 indicated medications (4 and 6 ), meanwhile the prescriptions in which no error was found had a mean of 6.30 indicated medications. $\mathrm{P}<0.001$.

Conclusion: According to the study findings, it could be established that when the number of prescribed medications is greater than 7 , there is an increased risk of making a prescription error. Further studies should carry out to look for other factors that influence medical errors in rheumatology clinics.

References:

[1] Aronson JK. Medication errors: definitions and classification. Br J Clin Pharmacol. 2009;67(6):599-604.

Acknowledgments

Disclosure of Interests: None declared

DOI: 10.1136/annrheumdis-2020-eular.2940 